\title{
CÂNDIDO, Maria Regina. (Org.) Banquetes, rituais e poder no Mediterrâneo antigo. Rio de Janeiro: P\&G Letras e Versos/NEA-UERJ, 2014. 267p.
}

A obra aqui resenhada, intitulada Banquetes, Rituais e Poder no Mediterrâneo Antigo e organizada por Maria R. Cândido, consiste em um produto do II Encontro Nacional e IV Nacional de Estudos sobre o Mediterrâneo Antigo, promovido pelo Núcleo de Estudos da Antiguidade (UERJ). Antes de tudo, o volume destaca um dos interesses mais claros do NEA: o de ver o Mediterrâneo como o principal palco de ação e conexão de múltiplas sociedades antigas - algo que remonta ao menos a 2009 (ano do I Encontro Nacional de Estudos sobre o Mediterrâneo Antigo) e que pontilhou a história acadêmica nacional recente com várias obras nesse sentido. ${ }^{2}$

O volume é dividido em quatro partes. A primeira delas reúne os artigos cujo objeto de estudo é, principalmente, a prática dos banquetes na Antiguidade, a segunda faz o mesmo em relação às práticas rituais e a terceira às relações de poder. Por fim, o artigo de José Maria G. de S. Neto fecha o volume sob a temática do ensino de História Antiga. É necessário deixar claro que, em sua totalidade, os conteúdos dos artigos não se limitam ao tópico da seção na qual foram situados, mas também tratam dos outros temas propostos pelo volume.

Dos sete artigos que compõem a primeira seção do livro, destaco três deles. O primeiro, escrito por María C. Colombani e intitulado "Banquete, dolor y subjetividade: las marcas de la philía", tem seu principal mérito na utilização do conceito de espaço "entre", cunhado por Martin Buber (Eu e Tu, 2001), como chave de leitura para a compreensão da ritualidade demonstrada em duas das cenas de banquetes da Odisseia. A autora lê as etapas de recepção de um estrangeiro (Telêmaco e Odisseu) e de sua inserção no contexto de um banquete, esse mantido por um anfitrião (Nestor e Alcínoo, respectivamente), como uma espécie de ritual. Esse ritual cria um espaço "entre" os dois

1 Mestrando, FAPESP, Universidade de São Paulo - São Paulo, Brasil. email: gacabe@hotmail.com

2 Ver, e.g. o Memórias do Mediterrâneo Antigo (Rio de Janeiro: UERJ/NEA, 2010), o Práticas Religiosas no Mediterrâneo Antigo (2 vols. Rio de Janeiro: UERJ/NEA, 2011) e o Práticas Alimentares no Mediterrâneo Antigo (Rio de Janeiro: UERJ/NEA, 2012), todos organizados por Maria R. Candido. 
indivíduos, espaço esse que possibilita o reconhecimento de ambos como pares e, assim, um diálogo entre iguais. A meu ver, o argumento principal da autora - de que esse processo permite que a dor sentida pelo hóspede/estrangeiro seja atenuada pela sua inserção no círculo social do anfitrião - é bem baseado, mas menos seminal que a chave de leitura ali definida, cujo teste em outros contextos pode apresentar resultados interessantes.

Nessa seção também podemos destacar o trabalho de Daniel Ogden, intitulado "The Banquet of Darius and the Transfer of the Persian Throne to Alexander the Great in the Alexander Romance". O autor vê duas releituras do mito fundacional da dinastia macedônica dos argéadas, esse em sua versão apresentada por Heródoto em suas Histórias (8.137-8). O primeiro caso estudado, o Romance de Alexandre (c. século III d.C.), de autoria anônima, narra o episódio que dá início à conquista alexandrina do Império Aquemênida através de uma narrativa carregada de metáforas. Tal narrativa toma uma série de elementos da história herodoteana supracitada - elementos esses que não cabem nessa breve síntese. O segundo caso estudado é o Romance de Ardeshir (meados do século VI d.C.), também de um autor anônimo. A parte da narrativa analisada por Ogden conta o início mítico da fundação da dinastia sassânida, mais especificamente quando essa derruba sua precedente, a dinastia parta. O herói da narrativa, Ardeshir, para se estabelecer como rei, segue episódios interessantemente semelhantes aos que os argéadas seguiram para se estabelecer no trono macedônico e que reaparecem na conquista da Pérsia no Romance de Alexandre. Temos, portanto, um trabalho notório sobre a recepção dos "clássicos" na própria Antiguidade; um trabalho que cobre uma tradição de pelo menos dez séculos de vida.

O terceiro artigo que destaco é o escrito por Anderson M. Esteves, intitulado "O Banquete de Tigelino: Um Topos de Corrupção de Costumes". Aqui vemos o autor articular (exemplarmente) as narrativas de Suetônio, Tácito e Dião Cássio sobre um episódio polêmico associado a Nero, o banquete de Tigelino. $\mathrm{O}$ autor procura mostrar como tais narrativas são esculpidas - tanto com a escolha dos termos usados quanto com o posicionamento dos argumentos dentro dos textos - de modo a caracterizar o imperador como possuidor de uma moralidade tão corrompida que, implicitamente, o torna o principal suspeito pelo incêndio de Roma em 64 d.C.. Uma contribuição de fato exemplar sobre a construção da imagem neroniana e dos valores morais associados a esse processo.

A seção sobre a prática de banquetes possui ainda quatro outros artigos, mas uma análise pormenorizada de cada um deles não cabe aqui. Basta, portanto, 
tecer alguns comentários sobre eles de modo que o leitor não desconheça seus principais conteúdos. O artigo de Maria R. Candido ("Os Gregos, O Banquete, e a Arte da Boa Mesa") exibe uma proposta e estudo: relacionar um conjunto de "inovações" nas práticas alimentares helênicas - mais especificamente a substituição de carnes por peixes considerados "exóticos" nos menus dos simpósios gregos - com a hegemonia mantida por Atenas no Egeu durante o século $\mathrm{V}$ a.C., que centrou no Pireu rotas de comércio que davam à "aristocracia" ateniense acesso a alimentos de aquisição mais difícil. O trabalho de José Roberto de P. Gomes ("Anacreonte e o Komós Festivo na Cratera de Copenhagen") busca uma conexão entre elementos da tradição antiga a respeito do poeta lírico Anacreonte e a iconografia de uma cratera ateniense de figuras vermelhas, atribuída ao pintor Cleófrades e datada do final do século VI a.C.. O artigo escrito por Norma M. Mendes (“Os Banquetes como Discursos de Romanização") assume uma posição muito mais teórica, sendo seu argumento principal o de que a romanização e as ações que a levavam à cabo (dentre elas a prática de banquetes em moldes romanos) permitiram aos indivíduos a criação de discursos compartilhados e, assim, de um espaço de diálogo entre duas culturas (a "local" e a "romana"). No último capítulo da seção ("São Patrício e a Festividade Pagã no Banquete da Província de Tara: religião e sociedade na Early Christian Ireland a partir da obra de Muirchú Moccu Machteni"), Dominique Santos vê no capítulo 15 da Vita Sancti Patricii, aqui traduzido ineditamente para o português, a utilização de estratégias de conversão imiscuídas a narrativas com elementos tradicionalmente pagãos, isso com o objetivo de torna-las mais facilmente compreendidas por seu público alvo - justamente os pagão da Irlanda do século VII d.C..

Da segunda seção do livro, sobre as práticas rituais antigas, destaco o artigo de Mario Torelli, intitulado "Gli Spetacoli Convivali di Etá Classica: Documenti Archeologici su Possibili Fatti Genetici e Sviluppi". Tratando dos banquetes na Grécia do Período Arcaico, Torelli busca (principalmente através da Arqueologia) a genealogia de suas práticas e de sua configuração. Em um primeiro momento, o autor volta os olhos para a iconografia de relevos assírios e destaca ali a origem de certos elementos do banquete, dentre eles a relação deste com as práticas religiosas - modelo esse adotado posteriormente, no início do século VII a.C.. Depois disso, Torelli se preocupa evidenciar como as práticas simposiastas tomada em seus moldes asiáticos são transformas de acordo com as especificidades de cada localidade, isso considerando tanto arquitetura doméstica quanto as cenas em vasos gregos do século VI a.C.. Entretanto, segundo Torelli, um elemento "duro de matar" teria sido o "espetáculo" que tais eventos haviam obtido de seu primeiro molde: ao menos na Etrúria, onde o conservadorismo era maior, elementos cênicos e musicais 
permanecem nas iconografias de cerâmicas lá encontradas em contextos do século $\mathrm{V}$ a.C.. Esse elemento, como já foi dito, sobrevive ou desaparece em diferentes contextos gregos, o que faz da Etrúria um local onde se pode ver melhor preservadas certos elementos mais arcaicos do banquete. $\mathrm{O}$ único elemento suspeito é justamente essa unidade etrusca, que faz do banquete etrusco algo sem nenhuma idiossincrasia local, praticamente o oposto puro da diversidade grega.

Dois outros artigos também compõem a segunda parte do volume. O escrito por Cláudia B. da Rosa ("Fortuna Muliebris: Construindo os Limites de Roma") contextualiza a retomada da história de Coriolano e da construção do templo de Fortuna Muliebris, contadas segundo Tito Lívio (2.40), no período da "restauração moral" promulgada por Augusto. Já o artigo escrito por Renata R. Sancovsky ("Leituras sobre o Corpo na Alta Idade Média: Rituais e Discursos Rabínicos entre os Séculos IV e V d.C."), talvez o mais bem escrito do volume, analise a multiplicidade de elementos presentes na pregação rabínica do início da Idade Média e seus contrastes com a teologia patrística ocidental, destacando continuidades e transformações culturais que influenciavam as comunidades judaicas ocidentais no período.

A terceira seção do livro, dedicada às relações de poder, é aberta pelo artigo "El Arte de Los Pisistrátidas: Poder, Construcción y Despliegue Ritual en la Atenas Arcaica", composto por Ana Iriarte. A autora retoma o ponto de vista que enxerga o período pisistrátida como uma época especialmente próspera no quesito cultural, mas adiciona a isso a caracterização desse elemento como uma ferramenta de consolidação do poder tirânico. Em outras palavras, se por um lado a demonstração dos tiranos de seu apreço pelo povo (deixado às claras, dentre outras ações, pelo mecenato de festivais e monumentos) parecia garantir-lhes seu apoio e lhes conceder um semblante democrático, por outro lado, se diversas medidas tomadas durante a tirania pisistrátida forem analisadas na estrutura na qual estavam inseridas, a conclusão é diferente. Segundo Iriarte, apesar de tais ações terem sido realizadas ao lado do discurso em favor das massas e de modo a distanciar o tirano de uma associação com a aristocracia, essas ações, na verdade, não diminuíram em nada o poder e a influência das oligarquias, apenas mudaram superficialmente as regras de um mesmo jogo de poder político.

O segundo capítulo desta seção que destaco aqui é o intitulado "Amicitia e Commendatio no Epistolário Pliniano", da autoria de Renata L. B. Venturini. Considerando as cartas de Plínio, o Jovem, a autora busca evidenciar os mecanismos pelos quais a amicitia e o commendatio faziam funcionar e reproduziam o sistema de poder na Roma imperial. Entretanto, o artigo 
ultrapassa em muito os objetivos propostos. Encontramos ali uma boa análise sobre a transformação do significado das ordines romanas; de como, mesmo depois da centralização do poder no imperador e das reformas de Augustos, seus membros articulam as prerrogativas a eles concedidas de modo a manter sua gravitas dentro do sistema político romano. Uma boa introdução ao estudo das estruturas do patronato político romano e à sua práxis.

A seção sobre as relações de poder contém ainda outros três artigos. O escrito por Julián Gallego ("Atenas y Tebas em el Edipo em Colono: Poder Político, Guerra Exterior y Sedición Internas") usa elementos intratextuais e extratextuais da peça sofocleana Édipo em Colono para evidenciar um debate implícito dentro da obra: a existência de uma stasis dentro da Atenas do final do século V a.C., posterior ao golpe oligárquico de 411 a.C.. A contribuição de Carlos Eduardo da C. Campos ("Nicolau de Damasco e Caio Otávio: Entre Redes Sociais e Discursos"), destaca a proficuidade que o estilo literário biográfico possui no sentido de reconstruir as redes sociais dos biografados, fazendo isso usando como exemplos as biografias augustanas do século I a.C., principalmente a de Nicolau de Damasco. Por fim, temos o artigo escrito por Cláudio U. Carlan ("As Transformações no Mundo Mediterrâneo Durante o Baixo Império"), que possui um caráter majoritariamente narrativo sobre as disputas políticas entre os imperadores romanos dos séculos III e IV d.C..

O último artigo, que fecha o volume com chaves de ouro, é o composto por José Maria G. de S. Neto, intitulado "O Teatro Ateniense na Formação do Historiador". O autor mostra como as obras clássicas, tomando As Troianas de Eurípides como exemplo, podem ser usadas em sala de aula para ir além dos formatos clássicos do ensino de História (informações dadas pelo professor e decoradas pelo aluno), mais especificamente, para auxiliar o desenvolvimento de uma "visão analítica do mundo e das realidades circundantes" (p. 250) nos alunos. Por mais que o artigo tenha sido composto inicialmente em 2013 (ano do evento que originou o volume), ele se torna ainda mais valioso hoje, principalmente por conta ao contexto no qual nos encontramos - isso é, durante a construção de uma nova Base Nacional Curricular que ameaça tolher as mesmas possibilidades educacionais delineadas por Neto.

Tomado em sua totalidade, o volume aqui tratado reúne as mais variadas abordagens e objetos de estudo, todos de fato inseridos dentro de um ou mais dos temas propostos (banquetes, rituais e poder) - algo, venhamos e convenhamos, difícil de se conseguir em coletâneas produzidas a partir de eventos acadêmicos. O único ponto que pode ser criticado nessa totalidade é o pouco espaço dado ao Mediterrâneo dentro do volume. Os artigos giram majoritariamente ao redor dos contextos gregos e romanos, com apenas 
algumas bem-vindas contribuições sobre outras conjunturas. Portanto, retomando o começo do artigo, o Mediterrâneo aparece aqui principalmente como palco de determinadas Histórias, sendo que seu papel de conector dessas Histórias aparece apenas dentro dos artigos e em poucos casos de maneira central. Falta, portanto, um capítulo conclusivo que interligue as diversas contribuições.

Se visto em suas particularidades, o volume aqui tratado reúne propostas de estudo e análises realmente seminais sobre diversos assuntos, algo que justificaria talvez uma segunda edição melhor revisada - há muitos erros de edição nos exemplares consultados, inclusive uma incongruência de paginação entre dois deles. Portanto, recomendo que os capítulos sejam lidos individualmente, tanto pelos interessados nos temas e objetos de estudo ali abordados quanto pelos que buscam uma introdução à bibliografia mais especializada. 